\title{
El resurgimiento de la neografía española y chilena de finales del siglo XIX en el marco de los movimientos internacionales de reforma ortográfica
}

\author{
Victoriano Gaviño Rodríguez ${ }^{1}$ \\ Universidad de Cádiz, España
}

\begin{abstract}
Resumen
El estudio de las acciones neógrafas de finales del XIX en España y Chile ha recibido escasa atención dentro de los debates ortográficos del español. Si bien es cierto que en ambos países la discusión sobre el asunto de la fijación ortográfica alcanzó mayor trascendencia en las décadas anteriores, aún faltan trabajos que analicen el interés de las acciones de un nutrido grupo de autores que en las dos últimas décadas del siglo reabren el tema ortográfico a ambos lados del Atlántico. Este trabajo, que pretende paliar en cierta medida esta deficiencia, tiene por objetivos: a) la delimitación de las interferencias e influencias entre los partidarios de la reforma en ambas naciones y, especialmente, b) la naturaleza y origen de sus propuestas, tomando para ello como referencia la importancia de la prensa escrita como medio de difusión de las ideas reformistas y la influencia ejercida en estos neógrafos por parte de los movimientos de reforma ortográfica que se promueven a nivel internacional, que sirvieron inicialmente de
\end{abstract}

\footnotetext{
1 Para correspondencia, dirigirse a: Victoriano Gaviño Rodríguez (victoriano.gavino@ uca.es), Facultad de Filosofía y Letras, Área de Lengua Española, Avda. Dr. Gómez Ulla, s/n, 11003, Cádiz, España. ORCID 0000-0002-6315-6884.
} 
impulso y defensa de los intereses reformistas en países como Francia, Inglaterra o Alemania, y son usados posteriormente como paraguas para la continuidad y desarrollo de la ideología reformista en países como España y Chile, donde estos neógrafos intentan una vez más la ejecución de sus reivindicaciones ortográficas en un periodo en que la Real Academia Española ha consolidado plenamente su doctrina en los distintos ámbitos sociales.

Palabras clave: historiografía lingüística, neografía, ortografía española, prensa española, Real Academia Española, siglo XIX.

The Resurgence of Spanish and Chilean neography at

THE END OF THE 19TH CENTURY WITHIN THE FRAMEWORK OF INTERNATIONAL MOVEMENTS FOR ORTHOGRAPHY REFORM

\begin{abstract}
The study of the neographic actions in the late nineteenth century in Spain and Chile has received little specific attention within the discussions focused on orthography reform. Although this topic reached greatest significance in previous decades, there is still a lack of studies that analyze the interest of the neographic actions on both sides of the Atlantic. The objectives of this work are a) the delimitation of interference and influences among supporters of reform in both nations and, especially, b) the nature and origin of their proposals, taking as a reference the importance of the written press as a means of disseminating reformist ideas and the influence exerted on these neographers by the Spelling reform movements at the international level, which initially served to promote and defend reformist interests in countries like France, England, Germany and, finally, Spain and Chile, where these neographers attempt the execution of their orthographic claims in a period in which the Royal Spanish Academy has fully consolidated its doctrine in different social spheres.
\end{abstract}

Keywords: linguistic historiography, neography, Spanish orthography, Spanish press, Spanish Royal Academy, $19^{\text {th }}$ century.

Recibido: $27 / 12 / 20$

Aceptado: 12/02/21 


\section{INTRODUCCIÓN ${ }^{2}$}

A finales del XIX, la Real Academia Española ha afianzado su autoridad como institución encargada de la regulación de la lengua española, tanto en España como en las jóvenes repúblicas americanas ( $c f$. Martínez Alcalde 2010: 76), en cuyas escuelas su doctrina es considerada la fuente principal de referencia para la enseñanza de la ortografía. Aunque esta hegemonía académica no parece propiciar la aparición de voces discordantes sobre la doctrina ortográfica, en las últimas décadas de siglo se produce un auge de las propuestas neógrafas que, agrupadas bajo una base ideológica más o menos unitaria, reivindican cambios en el modelo ortográfico de nuestra lengua en un contexto en el que parecen obviarse los múltiples intentos fallidos de propuestas similares de décadas anteriores, específicamente en España y Chile, países en los que se centra esta investigación. En lo referente a España, las acciones neógrafas habían disfrutado de una ocasión muy favorable para sus reivindicaciones en la etapa inmediatamente anterior, cuando, tras la caída de Isabel II, el 21 de octubre de 1868 se decretó la libertad en el uso de materiales destinados a la enseñanza y se abrió la posibilidad de que los maestros pudieran usar en su actividad docente otros manuales docentes distintos al Prontuario académico, cuyo uso había sido obligatorio desde las reales órdenes de 25 de abril de 1844, 1 de diciembre de 1844 y 22 de octubre de $1848^{3}$. La libertad de enseñanza durante el sexenio democrático causó, paradójicamente, el efecto contrario entre los partidarios del reformismo, que suavizaron su lucha y cesaron su actividad de peticiones de reforma en contra de la doctrina académica ${ }^{4}$ hasta que, a

2 Este trabajo se ha realizado en el marco del proyecto LinPePrensa. Ideas lingüisticas y pedagógicas en la prensa española del siglo XIX (ref. PGC2018-098509-B-I00), concedido por el Ministerio de Ciencia, Innovación y Universidades del Gobierno de España.

Frente a lo legislado en estas reales órdenes, el decreto de 1868, firmado por el ministro de Fomento Manuel Ruiz Zorrilla, estipula que "los Profesores deben ser también libres en la elección de métodos y libros de texto y en la formación de un programa, porque la enseñanza no es un trabajo automático, ni el Maestro un eco de pensamientos ajenos". En su artículo 16, establece que "los profesores podrán señalar el libro de texto que se halle más en armonía con sus doctrinas y adoptar el método de enseñanza que crean más conveniente" (Villalaín Benito 1997: 187-188).

4 Al margen de la interesante polémica que mantienen Gómez de Salazar contra Bosch y Condomines en la prensa escrita (fundamentalmente en las páginas de El Magisterio Español y El Fomento Balear, recogidas posteriormente en forma de folleto independiente titulado La neografía. Polémica sobre reformas ortográficas entre los señores Gómez de Salazar, Condomines y Bosch publicado en 1872), las acciones de los neógrafos durante el sexenio democrático flaquean y son escasas, de ahí que sus planes de reforma queden en el olvido 
partir del 26 de febrero de 1875, el terreno volvió a hacerse pantanoso para sus ideales, pues el rey Alfonso XII decretó la derogación de la libertad en el uso de manuales de enseñanza y la doctrina académica volvió a formar parte obligatoria en la enseñanza escolar. En esos mismos años, Chile ya se encontraba en una situación muy similar, tras los intentos de simplificación e implantación de una nueva propuesta ortográfica para el país. De hecho, ya en 1851 fue el propio Bello el que propuso al Ministro de Instrucción Pública el abandono de la reforma en el país (Martínez de Sousa 1991: 104). De este modo, el nuevo sistema apenas tuvo recorrido en la educación u otros ámbitos como el de la prensa o los organismos oficiales, donde el seguimiento de las doctrinas ortográficas académicas fue prácticamente unánime. El respaldo a la doctrina de la RAE se vio además favorecido por dos significativas acciones de la década de los ochenta: por un lado, la consulta que en 1884 realizó el Ministerio de Instrucción Pública al Consejo Superior de Instrucción Pública al respecto de la conveniencia de reimprimir ejemplares de la Ortografía académica para su uso en las escuelas; por el otro, la fundación, al año siguiente, de la Academia Chilena correspondiente de la española, en cuyos propósitos se encontraba la defensa de la ortografía académica en aras de la unidad idiomática.

Aunque podríamos pensar que las propuestas de reforma de finales de siglo, tanto en España como en Chile, afloran como una reacción natural al apoyo gubernamental y legislativo a la Academia y sus imposiciones doctrinales ${ }^{5}$, no parece que esta sea una razón suficiente en sí misma para que los partidarios del reformismo saquen a la luz sus anhelos y reivindicaciones en un momento en que las doctrinas académicas están tan extendidas en todos los distintos ámbitos de las sociedades española y chilena, máxime cuando en las décadas anteriores se habían producido tantas acciones y apenas se habían contabilizado hitos de importancia para la reforma. ¿Qué hace, así pues, que en esta nueva circunstancia adversa se lleve a cabo un resurgimiento de las propuestas de reformas a fines de siglo? Para responder a esta pregunta, es necesario ampliar nuestro foco más allá de las fronteras de cada uno de estos países, desde una perspectiva más amplia y abarcadora que nos permita visualizar el apoyo ideológico y el avance científico que en este periodo muestran las sociedades internacionales de fonética y los distintos movimientos internacionales de reforma ortográfica en países

en un periodo favorable en que quizás podrían haber ejercido más presión para alcanzar sus pretensiones.

5 Esta es la idea que, por ejemplo, parecen defender Cáceres y Rojas (2019: 71) como origen del auge neógrafo en Chile. 
como Suiza, Francia, Bélgica, Alemania o Inglaterra, entre otros, que sirven para el establecimiento de haces de relación entre los distintos neógrafos a nivel internacional y como impulso solidario de sus anhelos de reformas. Todas las acciones desarrolladas en estos grupos, unidas a la importantísima difusión que la prensa escrita de estos años aporta a la neografía, son puntos clave de este nuevo reformismo, que primeramente se hace más intenso en lenguas como el inglés, el francés y el alemán (en cuyas ortografías además existía mayor discordancia entre grafía y pronunciación), pero que pronto penetra ideológicamente en las luchas por la reforma ortográfica en el ámbito hispánico en países como España y Chile, como intentaremos desgranar en esta investigación.

\section{LOS MOVIMIENTOS INTERNACIONALES SOBRE REFORMA ORTOGRÁFICA Y SUS ECOS EN LA PRENSA ESPAÑOLA}

A partir de mediados del XIX, se comienzan a constituir, especialmente en el continente europeo, algunas sociedades internacionales de fonética que impulsan el desarrollo de la disciplina y el estudio fonético las lenguas, de las que se deriva de manera natural la demanda de reformar las ortografías usadas en muchas de estas lenguas. La primera de estas sociedades surge en el ámbito del inglés, donde de manera temprana se funda en 1843 la Phonetic Society, que junto a otras como la American Spelling Reform Association, establecida en 1876, o la English Spelling Reform Association, fundada en 1879, reivindican la reforma de la lengua inglesa en Europa y Estados Unidos. Suecia, por su parte, cuenta con la Rœttstavningssœlskap, fundada en 1885 y destinada a la reforma de la ortografía sueca. En 1876 se crea el Allgemeiner Verein für Vereinfachte Rechtschreibung, dedicado a la simplificación de la ortografía alemana y cuyos movimientos de reforma tienen especial trascendencia en la prensa española: en este sentido, $E l$ Globo (núm. 278, 5 de enero de 1876: 14) informa de una conferencia de profesores en Dresde, donde los gobiernos federales habían encargado al filólogo alemán M. Raumer la redacción de un proyecto para la reforma ortográfica de aquella lengua. Más tarde, la prensa española da noticias de algunos desencuentros dentro del gobierno alemán a causa de la ortografía alemana (El Liberal, núm. 315, 11 de abril de 1880: 1). Del mismo modo, en 1881, otros periódicos nacionales, como La opinión (núm. 442, 9 de marzo de 1881: 3) o La Crónica Meridional (núm. 6316, 9 de marzo de 1881: 2), anuncian la celebración en septiembre de ese mismo año de un congreso 
internacional en Berlín para reformar la ortografía de los distintos idiomas con un ambicioso proyecto, pues - como se afirma en el anuncio- "su objeto es la composición de un alfabeto común, y la conformidad y el acuerdo para la formación de un idioma universal". La noticia es ampliamente divulgada en diferentes anuncios en El amigo (núm. 160, 13 de marzo de 1881: 4), El bien público (núm. 2399, 18 de marzo de 1881: 3), El eco de la provincia (núm. 449, 9 de marzo de 1881: 3) o La Unión (núm. 13, 3 de mayo de 1881: 98), donde también se indica la duración de tres días para el evento y se advierte de que a él acudirán sabios de Europa y América.

De todas estas nuevas sociedades, son las aparecidas en Suiza y Francia, centradas en la reforma de la lengua francesa, las que más éxitos cosechan en sus reivindicaciones y también las de mayor repercusión internacional, dada la trascendencia de sus logros y el eco que sus acciones reformistas tienen en las páginas de la prensa escrita. Suiza es uno de los primeros países en los que se producen movimientos de reforma ortográfica. Durante la década de los sesenta se van fundando a lo largo del país diferentes comités fonográficos que reclaman una ortografía racional y que en 1867 acaban agrupados en la denominada inicialmente Société néographique de Suiza y, dos años más tarde, Société néographique Suisse et étrangère, presidida por Edouard Raoux, profesor de la Académie de Lausanne. En los inicios de esta sociedad ejercen gran influencia las teorías de Ambroise Firmin Didot (1867), compartidas con Raoux por el propio autor y en las que persigue el perfeccionamiento de la lengua francesa por medio de una propuesta de simplificación de su escritura. En 1876, la sociedad pasa a denominarse Société Suisse de Réforme orthographique y se convierte en la responsable de apoyar los intentos de reforma en Francia e informar a las partes interesadas en Suiza.

En Francia, es el fonetista francés Paul Passy quien impulsa en 1886 la creación de la denominada Dhi Fonètik Tîtcer'z Asóciécon (The Phonetic Teachers' Association), a la cual se asocia la creación, en ese mismo año, de una revista titulada Dhi Fonètik Tîtcer (The Phonetic Teacher), que en el año 1889 pasa a denominarse La me:tr fonetik (Le Maître Phonétique), dirigida por el propio Passy y que sirve de órgano periódico para la propaganda de la importancia de la transcripción fonética en relación con la enseñanza de lenguas. En esa misma fecha de 1889, la asociación, cuya lengua oficial es el francés, también cambia su nombre al de Asosjısjõ Fonetik de Profesœr de Lāg Vivāt (Association Phonétique des Professeurs de Langues Vivantes). Es en enero de 1897 cuando pasa a denominarse Asosja:sjõ Fonetik Ẽtrrnasjonal (Association Phonétique Internationale), tal y como señala 
en sus trabajos M. K. C. MacMahon (1986) y Galazzi (2000)6 . La prensa española no es ajena a los debates y propuestas que sobre la reforma del francés se producen en el país vecino, de ahí que sean constantes las noticias al respecto de este tema en las páginas de muchos periódicos españoles. $L a$ correspondencia de España (núm. 10576; 7 de marzo de 1887: 2), entre otros, nos informa de la repercusión que alcanza el asunto de la reforma ortográfica en Francia, así como de la carta que Gaston Paris, miembro del Collège de France, envía a Paul Passy acerca de la utilidad y conveniencia de reformar la ortografía francesa, cuyos sentimientos son canalizados en los años siguientes a través de las acciones de la Societé de Réforme Orthographique, encargada específicamente de la reforma de la ortografía francesa ${ }^{7}$, así como de un conjunto de publicaciones (la ya mencionada $L e$ Maître Phonétique, el Bulletin de la Sociéte de Réforme orthographique o La nouvelle ortographe) que adoptan una grafía reformada propia y sirven de órganos para la reivindicación de los ideales reformistas. Es precisamente la Societé de Réforme Orthographique la encargada, entre 1889 y 1890, de adoptar un proyecto de petición de reforma a la Academia francesa, en el que se solicita la simplificación de la ortografía y su camino hacia una ortografía fonética ${ }^{8}$. La noticia, que aparece en diversos medios periodísticos franceses (cf., por ejemplo, Revue de Philologie française et provençale, Tomo III,

6 Esta asociación surge inicialmente en torno a un grupo de profesores de lenguas coincidentes en considerar la fonética como un elemento esencial para la enseñanza y cuyo sistema de transcripción fonética pasa a ser la grafía normal en la redacción de los números de su revista. De manera veloz, la asociación va creciendo y sus afiliados se multiplican. Desde sus inicios, sus miembros proceden mayoritariamente de Alemania, Inglaterra o Francia, aunque también de otros países como Portugal, Dinamarca, Bélgica, Finlandia, Suecia, Finlandia, etc. Poco a poco van aumentando en presencia, hasta que en 1898 la Asociación Fonética Internacional cuenta con 907 miembros (según lo indicado por Araujo en su sección de "Revista de revistas" de La España Moderna, núm. 116, 1 de agosto de 1898: 142), un número que alcanza los 953 en 1900 (The Maître Phonétique, núm. 1, enero de 1900: 1-24) y sigue creciendo aún en las primeras décadas del siglo XX.

Acerca de las diferencias entre la Societé de Réforme Orthographique y la Association Phonétique des Professeurs de Langues Vivantes, es el propio P. Passy el que nos aclara que, mientras esta segunda se encarga de la reforma de los métodos de enseñanza de lenguas, la primera se centra en la simplificación de la ortografía francesa (cf. La Tradition, núm. 8, noviembre de 1887: 251-253 y Le Temps, núm. 9378, 7 de enero de 1887: 2).

8 El proyecto es respaldado por 7000 personas y el encargado de su redacción es Louis Havet, autor muy activo a favor de la reforma en los años precedentes por medio de diversos artículos en prensa que, como suele ser habitual en la época, acaban siendo recogidos más tarde en forma de folleto individual en Havet (1890). En 1889 también aparece en la Revue de l'enseignement secondaire et de l'enseignement supérieur (núm. 1, 1 de julio de 1889: 24-31) la reproducción del contenido de la carta, así como un análisis de las reivindicaciones de los reformistas, que firma Jean Passy, y entre 1889 y 1891 se producen discusiones al respecto 
1889: 158), es difundida también en algunos periódicos españoles, como el veterano diario La Palma de Cádiz (núm. 27889, 19 de noviembre de 1889: 2) o El país (núm. 874, 17 de noviembre de 1889: 3), donde también se aprovecha para llevar a cabo un paralelismo con la irrisoria situación española, en la que después de tantos años aún no se han suprimido las "inutilidades" de nuestro idioma. No nos adentraremos en los pormenores de esta solicitud, pero conviene tener en cuenta que detrás del silencio de la Académie française se esconde una profunda división dentro de la institución en relación con este tema, donde se dan interesantes polémicas de acogida o rechazo de los cambios propuestos (La Época, núm. 13357, 28 de octubre de 1889: 3 y núm. 14691, 8 de agosto de 1893: 2; El Guadalete, núm. 10318, 30 de octubre de 1889: 3 , etc. $)^{9}$.

Entretanto, el asunto de la reforma ortográfica cobra interés también en Bélgica, donde en 1892 se crea la sección belga de la Societé de Réforme Orthographique, a la que se adhieren 370 miembros, y que en años posteriores apoya el movimiento reformista en Francia. Al mismo tiempo, esta sección prepara su propia propuesta para llevarla a la práctica con la celebración de una asamblea en la Escuela Normal de Bruselas, a la que acuden diversas personalidades. En ella, su director M. Sluys imparte una conferencia sobre el tema de la reforma de la ortografía y la democracia, en la que afirma que simplificar la ortografía es ayudar a la emancipación de las masas ( $L a$ Escuela Moderna, julio-diciembre de 1892: 77). El Heraldo de Madrid (núm. 903, 25 de abril de 1893: 1) también recoge en sus páginas la petición de M. Gréard para que se ejecute esta reforma en Bélgica, acompañando esta noticia de una crítica a las observaciones conservadoras que a este respecto emite el escritor M. Elwall en La Libre Critique de Bruselas, quien considera el proyecto como una amenaza y peligro a la unidad nacional. En 1893, llegan noticias a la prensa española del comienzo de la reforma por parte de la Academia francesa y sus acuerdos en relación con cambios en algunos elementos gráficos (El Correo de Gerona, núm. 151, 1 de agosto de 1893: 2; El isleño, núm. 11940, 1 de agosto de 1893: 2; núm. 11943, 4 de agosto de 1893: 3). Pero las aspiraciones de los reformistas son más amplias, así que

de la reforma en muchas revistas de temática especializada, como, por ejemplo, la Revue de philologie française.

9 Algunos académicos como Émile Littré (1873-1874), por ejemplo, son partidarios de cambios al respecto de algunas inconsistencias de la ortografía francesa, pero sus propuestas no son aceptadas inicialmente. La tendencia parece cambiar ligeramente unos años más adelante, cuando, con la publicación de la séptima edición del diccionario de la Academia (1877-1878), la institución parece relajar su conservadurismo y tolera la inclusión de algunas reformas. 
la Societé de Réforme Orthographique solicita al ministro de Instrucción Pública francés "reformar la enseñanza de la ortografía en las escuelas, suprimiendo gradualmente las anomalías más violentas y más difíciles de aprender" (Boletín de la Institución Libre de Enseñanza, núm. 438, 30 de septiembre de 1896: 277) ${ }^{10}$. A finales de siglo, la Revista de Extremadura (núm. III, 1 de mayo de 1899: 205) anuncia que la ortografía fonética se va haciendo sitio en Francia ${ }^{11}$ y son numerosas las noticias triunfales al respecto de sus logros en la reforma de su ortografía ( $c f$., por ejemplo, $E l$ íbero, núm. 61, 1 de noviembre de 1900: 903-904; núm. 62, 16 de noviembre de 1900: 914-916; núm. 63, 1 de diciembre de 1900: 932-934; núm. 64, 16 de diciembre de 1900: 951-953) ${ }^{12}$. Por su parte, Fernando Araujo informa del decreto del Ministro de Instrucción Pública de Francia que resuelve la reforma de la ortografía francesa a partir de los trabajos de la comisión constituida para tal efecto, así como del malestar mostrado por la Academia por no haberse contado con ella (La España Moderna, núm. 142, octubre de 1900: 185-186). No podemos ahondar en todos los elementos de interés sobre el asunto, pero esperamos que este breve recorrido sirva, al menos, como constancia de todo el eco que este inmenso debate sobre la lengua francesa deja en la prensa española, cuyos lectores asisten con expectación a las noticias sobre esta pugna entre reformistas de la ortografía y aquellos contrarios a ella, que se produce hasta bien entrado el siglo XX.

10 El contenido específico de esta petición puede verse en diversas publicaciones periódicas francesas, como, por ejemplo, la Revue des revues (vol. XVII, 1896: 67-74), La revue pédagogique (t. 29, julio-diciembre de 1896: 18-29) o el suplemento a la Revue Universitaire (15 de marzo de 1896).

11 También se habla, en esta ocasión, de la situación en Hispanoamérica.

12 Durante estos años, la prensa española también acoge diferentes artículos teóricos sobre el asunto, como el publicado en El Boletín de la Institución Libre de Enseñanza (núm. 318, 15 de mayo de 1890: 129-132; núm. 323, 31 de julio de 1890: 209-212; núm. 327, 30 de septiembre de 1890: 273-275; núm. 328, 15 de octubre de 1890:289-290) por parte de M. A. Sluys bajo el título de "La enseñanza de la lectura y de la ortografía", extraído de su libro Méthode analytique et synthétique de lecture et d'ortographe. Se trata de un artículo seriado destinado específicamente a la importancia de un buen método de lectura, pero en el que se aborda también la problemática que supone enseñar a leer en una lengua como el francés con un alfabeto con tantas irregularidades.

No faltan tampoco noticias que muestran cierta mofa con la trascendencia que toma el asunto ortográfico en Francia. En esta línea, El Cantábrico y El Guadalete informan de las elecciones municipales de París por medio de un artículo en el que, al hablar de la pertenencia de los candidatos a distintos partidos, se menciona, entre ellos, "al que fia la resolución de todos los problemas sociales en la reforma de la ortografía y al que ofrece lavar la cabeza á sus electores" (El Cantábrico, núm. 1829, 8 de mayo de 1900; El Guadalete, núm. 13721, 10 de mayo de 1900: 1). 


\title{
3. INFLUENCIA DE LAS SOCIEDADES DE REFORMA ORTOGRÁFICA EN EL RESURGIMIENTO DE LA NEOGRAFÍA ESPAÑOLA Y CHILENA
}

\begin{abstract}
La creciente ola de interés internacional por la reforma ortográfica pronto se hace notar en España, donde los reformistas, apoyados por la cientificidad que va adoptando la disciplina fonética ${ }^{13}$, muestran su afinidad con esta ideología y se adhieren a estos movimientos ${ }^{14}$, ya sea redactando textos reivindicativos o llevando a cabo otra serie de acciones que dan lugar al resurgimiento de nuevas propuestas de cambio ortográfico a finales del XIX. La prensa escrita se erige en el vehículo preferencial para la difusión de sus trabajos, el medio más adecuado para la popularización de sus ideas e intereses individuales ${ }^{15}$,
\end{abstract}

13 En este proceso destaca el lanzamiento del Alfabeto Fonético Internacional (Alphabet Phonétique International) en 1888, en cuya base existía la convicción firme por parte de estos profesores de lenguas de que el sistema de escritura utilizado para transcribir las distintas lenguas del mundo no se correspondía con su pronunciación. Su creación suponía una ayuda inestimable para la enseñanza de lenguas, pero también jugaba un papel fundamental en la adaptación que tanto Passy como otros fonetistas perseguían para adecuar letras y sonidos.

En palabras de P. Passy, "lo que distingue este movimiento de los anteriores es, en su conjunto, la parte que en él han tomado los lingüistas de profesión, y por tanto, el carácter de rigor científico que ha tomado y se acentúa cada día más" (Revista de España, Tomo CXIX, enero de 1888: 62). En este mismo punto insiste F. Araujo cuando menciona las distintas sociedades internacionales y afirma de ellas que "aspiran por uno ú otro procedimiento á sustituir á la actual escritura otra escritura razonada y, principalmente, en el más concienzudo análisis de los elementos fonéticos del lenguaje" (España y América, núm. 47, 20 de noviembre de 1892: 535).

14 En todas estas sociedades se instaura un sistema de captación de socios que funciona a la perfección desde las páginas de sus propias revistas, donde son constantes los anuncios para que todas las personas favorables a la reforma ortográfica se adhieran como miembros. Así, en La me:tr fonetik (vol. 6, núm. 6, junio de 1891: 84) puede verse la reproducción de uno de estos llamamientos por parte de la Sociéte de Réforme Orthographique: "La Sociéte de Réforme Orthographique fait appel a toutes les personnes qui désirent une réforme quelconque de l'orthographe française. Membres actifs, 5 fr. par an; adherénts, 2 fr.; adjoints, 0 fr. 50 . Les membres reçoivent le journal La Nouvelle Orthographe. S'adresser a M. Ch. Roussey, 23 rue Cujas, Paris, ou au bureau du M. F.".

15 Tal y como afirma Puche Lorenzo (2019: 66), a medida que avanza el XIX, la prensa deja de ser paulatinamente un medio destinado a la minoría culta del siglo anterior y adquiere nuevos valores en relación con la movilización social, el ámbito político, la formación, el entretenimiento o la mera información. En esa amalgama de funcionalidades en que confluyen sus distintos géneros textuales, se acrecienta el interés (no casual) de la propia sociedad por los asuntos ortográficos, que en esta última etapa del XIX guarda además estrecha relación con la aparición y desarrollo de los distintos movimientos internacionales sobre reforma ortográfica, cuyas ideas desembarcan en España y Chile a través de estos periódicos, que sirven de hilo conductor e incentivo del nuevo interés que este asunto vuelve a despertar en estos países. 
al tiempo que el vehículo idóneo para el intercambio ideológico entre estos intelectuales, que interactúan entre sí y entablan de este modo haces de relación social que van más allá del ámbito periodístico y los convierten en piezas clave en la discusión de estos asuntos en otros espacios sociales de opinión, como el de las distintas instituciones relacionadas con la vida cultural del país.

Precisamente en el seno de algunas de estas instituciones es donde se va consolidando paulatinamente en España todo este nuevo ambiente de interés internacional por la reforma ortográfica, que alcanza especial intensidad a partir de finales de 1884, cuando en algunas sociedades como el Círculo Filológico se celebran discusiones sobre ortografía castellana: en primer lugar, destaca el enfrentamiento dialéctico que sobre la ortografía se produce entre los Sres. Doce y Bentfeldt e Hilario Sánchez (La correspondencia de España, núm. 9766, 17 de diciembre de 1884: 1; El Pabellón Nacional, núm. 6706, 17 de diciembre de 1884: 3, etc.); en días cercanos, se realiza también en el Círculo Filológico un debate a partir de una memoria que sobre simplificación y reforma de la ortografía castellana presenta Casto Vilar $(E l$ Día, núm. 1645, 8 de diciembre de 1884: 1; El Imparcial, núm. 6294, 9 de diciembre de 1884: 3, El Liberal, núm. 1975, 11 de diciembre de 1884: 3). Un poco más tarde, a finales de ese mismo año, interviene en estos encuentros Tomás Escriche y Mieg, profesor de física y socio de El Ateneo Caracense de la ciudad de Guadalajara (cf. La Correspondencia de España, núm. 9771, 22 de diciembre de 1884: 1; El Ateneo Caracense, núm. 249, 5 de enero de 1885: 290) con la exposición de las ideas que sobre reforma ortográfica ya había defendido poco antes en su artículo "La ortografía fonética" ( $E l$ Ateneo caracense, 5 de octubre de 1884:259-264; 5 de noviembre de 1884: 267-270) ${ }^{16}$. Unos años más tarde, con la publicación seriada de su interesante artículo "Reforma de la ortografía castellana (dedicada á la Real Academia Española)" (Revista contemporánea, Tomo LXXV, vol. VI, 30 de septiembre de 1889: 561-580; Tomo LXXVI, vol. I, octubre, noviembre y diciembre de 1889: 24-38; Tomo LXXXVI, vol. II, 30 de octubre de 1889: 177-192; Tomo LXXVI, vol. III, 15 de noviembre de 1889: 308-318; Tomo LXXXVI, vol. 4, 30 de noviembre de 1889: 417-425) ${ }^{17}$, Escriche y Mieg se convierte

\footnotetext{
16 Aunque no he podido localizar ejemplares, parece ser que esta contribución adopta posteriormente forma de folleto y es publicada de manera independiente bajo el mismo título de La ortografía fonética, según se anuncia en El Volapük (núm. 1, 1 de enero de 1886: 12; núm. 3, 1 de marzo de 1886: 11; núm. 3, 1 de marzo de 1887: 15).

${ }_{17} \mathrm{Su}$ ensayo, que se divide en tres partes (defectos de los que adolece la ortografía castellana, proyecto de reforma propuesto y modo de realizarla), también ve la luz como obra
} 
en el primer abanderado del resurgimiento de la neografía en España en el marco de los movimientos internacionales de reforma, dando muestras de la influencia que en él ejerce su temprana pertenencia a las sociedades de reforma ${ }^{18} \mathrm{y}$ del conocimiento de las acciones reformistas llevadas a cabo en otros países:

Si somos poquísimos en España los que defendemos el fonetismo (no cuento á los mal avenidos con la ortografía, sin más razón que la de no haber sabido jamás practicar sus reglas), en el extranjero progresa con rapidez la idea, y he recibido ya algunos impresos fonéticamente en alemán y en francés (Revista de España, Tomo CXIX, núm. 471, enero de 1888: 62).

Junto a la figura de Tomás Escriche y Mieg, pronto otros autores españoles, como José Jimeno Agius, Fernando Araujo, Onofre Antonio de Naverán o Juan Bosch Cusí, siguen su estela en España, con aportaciones de distinta envergadura en las que se visualiza la influencia (directa o indirecta) de estas sociedades internacionales de reforma.

Aunque de modo más tardío, las propuestas reformistas alcanzan también su trascendencia al otro lado del Atlántico, toda vez que el asunto de la

independiente en 1889 en Madrid, si bien algunos estudios -como el de Esteve Serrano (1982: 86)- han popularizado su segunda edición del año 1890 en Bilbao, que es la que también recoge Carlos Cabezón (1896: 6) en su trabajo de tentativa bibliográfica sobre los neógrafos.

18 El contacto de los españoles con las sociedades internacionales de reforma es anterior al de los autores chilenos, si bien su incorporación en ellas es minoritaria y menos duradera en el tiempo que la de los chilenos. En el caso concreto de Tomás Escriche i Mieg, aparece como miembro de Dhi Fonètik Tîtcer'z Asóciécon en los listados que la revista de la asociación publica entre finales de 1887 y principios de 1888 (Dhi Fonètik Tîtcer, núm. 20, diciembre de 1887: 49; núm. 1, enero de 1888: 26). Un año más tarde, figura, junto a su nombre, el de otro importante neógrafo español, Fernando Araujo (La me:tr fanetik, núm. 1, enero de 1889: 2), cuya proyección nacional e internacional es cada vez más relevante. En los años siguientes, ambos autores constan como miembros activos (La me:tr fonetik, núm. 1, enero de 1890: 1; núm. 1, enero de 1891: 1) y no es hasta 1892 cuando se incorpora un tercer miembro de España, en este caso, Donato Sotés (La me:tr fonetik, núm. 1, enero de 1892: 7). La nómina de miembros españoles ligados a la asociación aumenta en número hasta los seis en 1893: F. Araujo, T. Escriche i Mieg, D. Sotés, M. Díaz-Rubio, V. Fejada y J. G. Hernández (La me:tr fonetik, núm. 1, enero de 1893: 8) y alcanza los catorce en 1894: de los anteriores, todos continúan a excepción de Fejada, cuyo nombre desaparece del listado; se incorporan D. Arráiz, P. A. Berenguer, E. Ruiz Fornell, J. Gómez Jareno, R. Andrés Monedero, M. C. Montijano, A. Muñoz, J. M. Paniagua y J. Ostenero Velasco (La me:tr fonetik, núm. 1, enero de 1894: 9). A partir de 1895, la lista va disminuyendo y entre los españoles empiezan a ser más frecuentes las bajas que las altas. De entre las nuevas altas de miembros, destaca el ingreso de Menéndez Pidal en 1898 (cf. La me:tr fonetik, núm. 1, enero de 1898: 14). Los nombres de Escriche y Mieg y Araujo perduran todo el siglo XIX y siguen su afiliación en el XX. 
lengua y el de la estandarización lingüística estaban aún latentes por el lugar central que habían ocupado en el debate político de las décadas anteriores de estas naciones. En el caso concreto de Chile, las acciones reformistas de fines de siglo se sienten con una pasión e intensidad menor que la de aquellos acontecimientos que se vivieron en el país entre 1830 y 1850 a partir de las propuestas de reforma de la ortografía llevadas a cabo desde el exilio londinense por Juan García del Río y Andrés Bello en su artículo "Indicaciones sobre la conveniencia de simplificar y uniformar la ortografía en América" (Biblioteca Americana, tomo I, 1823: 50-62; El Repertorio Americano, tomo I, octubre de 1826: 27-41). Sus inicios se producen, en primer lugar, de la mano de R. Lenz, que, tras llegar en 1890 a este país desde Alemania -donde seguramente estuvo influido por su movimiento ortográfico- publica en 1891 sus "Observaciones sobre la ortografía castellana" 19 , un texto que sirve de antesala del nuevo movimiento neógrafo en Chile; en segundo lugar, por lo sucedido a raíz de la publicación el 13 de julio de 1892 de un artículo de Carlos Cabezón, miembro de la Sociedad de Reforma Ortográfica, titulado "Abiso a los qomerziantes" en La Unión de Valparaíso (13 de marzo de 1892: 3), que, aunque por su contenido y destinatarios, debía ser ajeno a la polémica -se trata de un aviso para los artesanos de la zona-, es caracterizado como un acto práctico de ideología lingüística a favor de la neografía, más aún cuando venía de la pluma de alguien que ostentaba un cargo público. Sus palabras son percibidas como un desafío por aquellos contrarios a la reforma que determina la aparición de reacciones en contra del uso de una ortografía diferente a la chilena y acaba provocando una honda polémica en la prensa al respecto de qué ortografía debía usarse en Chile ( $c f$. Contreras 1994: 61-65). Con ello, se reactiva el debate ortográfico en el país y la propuesta de la denominada 'ortografía rrazional' -como indica en su estudio Villarroel (2019a: 134; 2019b: 355)que tiene en Chile a Carlos Cabezón y Carlos Newman (bajo el pseudónimo de Franzisqo Enrriqez) como sus autores más conocidos, que apoyan la defensa de sus peticiones en sus antecesores más inmediatos en Chile, Sarmiento y Bello ${ }^{20}$, pero a los que se suma también el importante aporte ideológico de algunos de los nuevos reformistas españoles -especialmente,

19 Este trabajo es inicialmente publicado en el periódico La Libertad Electoral. La versión que he consultado es la incluida con posterioridad en su obra De la ortografia castellana (Lenz 1914).

20 En este marco de influencias, conviene también mencionar la ejercida por su maestro E. de la Barra (1897a: 11), que en alguna ocasión agradece públicamente la labor de estos neógrafos: "El puesto de honor en esta nueva jornada, corresponde a mis discípulos Karlos Newman i Karlos Kabezon, quienes valientemente adoptaron el sistema completo en sus 
Escriche y Mieg o Jimeno Agius, aunque más tarde, también la de otros como Fernando Araujo y Onofre Antonio de Naverán- cuyos textos son imprimidos y/o difundidos en el país ${ }^{21}$ no solo por su coincidencia con los postulados de los reformistas americanos -como acertadamente han afirmado Contreras (1993: 225-230) y Martínez Alcalde (2010: 74)-, sino también como impulso para la reactivación de la neografía en el continente americano, dada la falta de otras aportaciones en estos años en el país que alentaran el movimiento. De este modo, se proporciona a los reformistas chilenos la pieza necesaria para hacer funcionar el engranaje de la reforma, una vez que ya a nivel internacional se habían consolidado algunas sociedades (como la Asociación Fonética Internacional o la Sociedad de Reforma Ortográfica, por ejemplo), a las que también se adhieren poco a poco los neógrafos chilenos ${ }^{22}$.

escritos, i como pioneers del far-West, van tendiendo los rieles del progreso por rejiones desiertas, seguros de su obra, fecunda en buenos resultados".

21 La muestra de textos recogidos en Cabezón $(1896 ; 1897)$ es buen ejemplo de estas influencias: a los nombres de autores americanos como Bello, Amunátegui, Lenz o E. de la Barra, se unen los de activistas de estas sociedades internacionales de reforma (Havet o Müller), además de españoles como Naverán (1893), Escriche y Mieg (1889; 1890), Jimeno Agius (1892a; 1892b); Araujo (1894), etc., cuyas publicaciones circulan por el país o son directamente imprimidas en Chile.

22 La incorporación de miembros del otro lado del Atlántico a estas sociedades es algo más tardía, pero su presencia en ellas se sustenta durante un tiempo más prolongado. Al margen de los miembros procedentes de EE.UU. y Canadá que formaban parte de la American Spelling Reform Association, en Dhi Fonètik Tîtcer'z Asóciécon hay una ausencia de miembros procedentes del ámbito hispanoamericano hasta 1893, fecha en la que aparecen algunas afiliaciones desde Chile. Sus primeros miembros son R. Lenz y L. Branes (La me:tr fonetik, núm. 1, enero de 1893: 7), a los que se unen un poco más tarde los nombres de L. Banderas, A. Díez, M. Molina, E. Sepúlveda y L. Trujillo (La me:tr fonetik, núm. 1, enero de 1894: 14). En 1895 los socios de Chile alcanzan el número de once: a los ya mencionados, se unen J. Brosseau, E. Figueroa, F. Litten y O. Ludwig (La me:tr fonetik, núm. 1, enero de 1895: 15). En los siguientes años, el número sube exponencialmente, alcanzando los veintisiete miembros en 1896: R. Lenz, Hernando Adriazola, Leonidas Banderas, Luis Branes Debierre, Jorge Brosseau, Ildefonso Bustos, Francisco Carey, Arsenio Casanova, Rafael Cavada, Antonio Diez, Emiliano Figueroa, Daniel Fredes, Dorila González, F. Kanssen, F. Litten, Óscar Molina, Rosa Amelia Muñoz, Ricardo Muñoz, Pedro Juan Ojeda Rivera, Armando Ovalle de la Fuente, Josias Paredes, Luis A. Román, Enrique Sepúlveda, Juan Tapia Mendoza, Ramón Vargas, Carlos Woehlk y Luis E. Zúñiga (La me:tr fonetik, núm. 1, enero de 1896: 18). La cifra asciende a cuarenta y siete en 1898 (La me:tr fonetik, núm. 1, enero de 1898: 21-22), cincuenta en 1899 (La me:tr fonetik, núm. 1, enero de 1899: 22-23) y cincuenta y seis en 1900 (La me:tr fonetik, núm. 1, enero de 1900: 22-23). 


\section{IDEOLOGÍA REFORMISTA DE LOS NEÓGRAFOS ESPAÑOLES Y CHILENOS DE FINES DE SIGLO}

La reaparición de las acciones reformistas españolas y chilenas en el marco de los movimientos internacionales de reforma no conlleva muchos cambios en los planteamientos de las propuestas ortográficas sobre el español, a excepción de la novedosa idea de creación de una sociedad de reforma ortográfica a imitación del modelo ya conocido de estas asociaciones internacionales. Al margen de este aspecto, la ideología reformista de estos neógrafos se caracteriza, en líneas generales, por su continuidad en el tratamiento del debate ortográfico, que sigue versando sobre los ya conocidos asuntos del modelo concreto de reforma que se propone, el plan para llevarlo a cabo o el papel desempeñado por la Academia en este proceso.

\subsection{CREACIÓN DE UNA SOCIEDAD DE REFORMA ORTOGRÁFICA CON SEDE EN ESPAÑA}

En el caso concreto de España, la idea más novedosa y central que ronda la cabeza de los nuevos reformistas es, sin duda, la creación de una sociedad de reforma ortográfica con sede en el país, al estilo de la existente en otras naciones para otras lenguas. Esa tendencia, que no se manifiesta en la neografía chilena, ya contaba en España con algo de recorrido cuando en 1872 se había creado tímidamente una asociación para la reforma de la ortografía en Palma de Mallorca, de la que se da noticia en las páginas de El Progreso. Periódico político (núm. 1095, 23 de octubre de 1872: 2), si bien el asunto empieza a tomar importancia en el momento en que algunos intelectuales promueven, tanto en el seno de algunas instituciones como en sus escritos, su creación a nivel nacional:

Agítase la idea de formar una Asociación española para la reforma de la Ortografía, sobre la base de la escritura fonográfica, representando cada sonido por un solo signo y eliminando todos aquellos que no representan ninguno y solo tienen un valor etimológico. Algunos individuos del Ateneo Carecense se piensan adherirse al proyecto (Revista del Ateneo Carecense y Centro Volapukista español, núm. 12, marzo de 1891: 124).

Escriche y Mieg es el primero en formular la importancia de la creación de una sociedad de reforma ortográfica en España, convencido del papel 
fundamental que en este proyecto de fonografía ${ }^{23}$ castellana podría jugar ante la falta de empatía que el proyecto de reforma encontraría en la Academia:

$\mathrm{Si}$, pues, la reforma no ha de venir de arriba, será preciso que proceda de abajo, donde hay también fuerza y autoridad que hasta pueden superar en mucho á las de la Corporación Soberana, á condición, no obstante, de que se aúnen los esfuerzos; porque es bien evidente que los conatos individuales nada pueden. Y de ahi la necesidad imperiosa de crear una Sociedad de Reforma Ortográfica, que acometiendo con fe y decisión la tarea de propagar la fonografía para plantearla, bien de una vez, ó mejor gradualmente, excogite y ponga en ejecución los medios apropósito para lograrlo (Revista contemporánea, Tomo LXXVI, vol. III, 15 de noviembre de 1889: 317).

En una línea muy similar, Jimeno Agius se muestra escéptico ante las posibilidades de que el gobierno español adopte decisiones sobre la reforma, de ahí que sienta la necesidad de "recurrir al único medio de que disponen los pequeños para competir con los grandes, al de asociarse" (Revista contemporánea, Tomo LXXXI, vol. V, 15 de marzo de 1891: 481). Aunque -según su opinión- lo idóneo sería la creación de una sociedad que publicara numerosos impresos ajustados a la nueva ortografía que sirvieran para "acostumbrar la vista de la generalidad de las gentes á la nueva ortografía", Jimeno Agius es consciente de la escasa voluntad de asociacionismo entre los españoles, de ahí que se resigne a aceptar al menos la constitución informal de lo que él denomina una liga para la reforma de la ortografía:

Pero tampoco es un inconveniente que no llegue á darse forma más ó menos solemne á la Liga. Bastará suponerse establecida y que se considere miembro suyo todo el que quiera contribuir á la realización del fin á que aspira. El que diere algo á la imprenta, ajústese á la nueva ortografía y adicione á su nombre, al consignarlo en la portada del libro, esta frase: De la Liga para la reforma de la ortografía (Revista contemporánea, Tomo LXXXI, vol. V, 15 de marzo de 1891: 482).

23 En sus propias palabras, la fonografía consiste en "escribir exactamente como se pronuncia” (Revista contemporánea, Tomo LXXV, vol. VI, 30 de septiembre de 1889: 563). 


\subsection{PAPEL DE LA ACADEMIA PARA LA EJECUCIÓN DE LOS CAMBIOS ORTOGRÁFICOS}

La ideología de los neógrafos de fines de siglo al respecto de la funcionalidad de la Academia y su papel en la propuesta y desarrollo de la reforma ortográfica es totalmente opuesta en uno y otro lado del Atlántico y entronca con las experiencias vividas anteriormente en cada uno de los países con sus reformas. De un lado, los reformistas españoles, conscientes de la autoridad de la Academia en la sociedad de la época, abanderan una tendencia más conservadora en la que intentan rehuir de la pugna con la Academia y ganarse su confianza para una posterior adhesión al proyecto ( $c f$. Gaviño Rodríguez 2020a:). En este sentido, Escriche y Mieg defiende lo que sigue:

Quiero, pues, en primer término, aunque sin prisa ni impaciencia, que nos ganemos la adhesión de la Academia [...] Y como la causa de la fonografía es la buena, y las personas de talento é ilustradas no pueden menos de rendirse á las razones, es lo probable que llegáramos á tener la adhesión de la Academia Española, que volviendo á sus antiguas tradiciones, podría entonces tomar la dirección del movimiento reformista (Revista contemporánea, Tomo LXXXVI, vol. IV, 30 de noviembre de 1889: 418) ${ }^{24}$.

Esta misma postura es secundada por Jimeno y Agius que en su artículo "Reforma de la ortografía castellana" (Revista contemporánea, Tomo LXXXI, vol. V, 15 de marzo de 1891: 465-483; Tomo LXXXI, vol. VI, 30 de marzo de 1891: 582-596) intenta posicionar a la Academia del lado de los reformistas, recordando las múltiples modificaciones, cambios o vacilaciones de la institución en relación con la grafía castellana. En este mismo aspecto insiste Araujo (1894: 65), quien se muestra confiado de que

24 Esta postura no era novedosa en el ámbito de las reformas internacionales, donde ya Havet afirma lo siguiente para el francés: "Il faut une réforme aceptable pour tout le public; c'est-a-dire qu'il la faut d'abord aceptable pour l'Académie française" ("La réforme orthographique", en La nation, núm. 1068, 22 de marzo de 1887: 2). Tampoco es la primera vez que se postula en España, pues autores como Francisco Ruiz Morote (cf. El Magisterio. Periódico de educación y enseñanza, núm. 7, 1860: 76-82; núm. 13, 1860: 150-154) ya habían intentado abandonar la confrontación con la RAE cuando, tras la oficialización de su ortografía, los maestros se encontraban en una posición de subordinación ante una corporación erigida ahora como el órgano regulador de la lengua española y su enseñanza y estos consideraban que cualquier contienda con la Real Academia Española estaría condenada nuevamente al fracaso ( $c f$., a este respecto, Gaviño Rodríguez 2020b). 
"la Akademia rekojerá su abandonada bandera, i volverá a ponerse al frente del mobimiento neográfiko fonétiko".

Del otro lado, los reformistas chilenos defienden una postura más combativa y reaccionaria con la docta institución; quejosos por el terreno ganado por la doctrina académica en detrimento de la propuesta de Bello, los reformistas no buscan la adhesión de la Academia al proyecto, pues se la considera incompetente para abordar este asunto. Esta idea es abanderada por el propio Lenz (1914: 22), para quien "la Academia no tiene ni sombra de competencia en materias lingüísticas", pero es seguida en general por otros neógrafos chilenos como, por ejemplo, Carlos Cabezón (1892: 56): "la misión de la Aqademia no es iniciar reformas de ninguna qlase, por mas razonables y necesarias qe las qrea: su papel es acoger qomo bueno lo qe qomo tal es aceptado por el públiqo". En esta línea, propone que sea el público de a pie, sin nada que arriesgar ni demostrar, el que inicie y ponga en práctica la reforma (y no la Academia) ${ }^{25}$.

\subsection{MODELOS DE REFORMA ORTOGRÁFICA}

Uno de los inconvenientes que tradicionalmente se ha señalado en las propuestas reformistas es la ausencia de un modelo común de reforma que sirviera de base para sus reivindicaciones, aspecto este en el que colisionan también estos nuevos neógrafos, cuyas propuestas de modelos de reforma son tan dispares entre sí que hace difícil la consideración de "racional" para la ortografía que proponen.

La primera propuesta de reforma es de Escriche y Mieg, que en su artículo "Reforma de la ortografía castellana (dedicada á la Real Academia Española)" (Revista contemporánea, Tomo LXXV, vol. VI, 30 de septiembre de 1889: 561-580; Tomo LXXVI, vol. I, octubre, noviembre y diciembre de 1889: 24-38) plantea un modelo que, a pesar de no ser considerado por

25 Por encima de la utilidad y ventaja de los razonamientos del fonetismo, Gómez de Baquero había propuesto una idea similar a la chilena unos años antes en España, cuando se mostraba plenamente convencido de que lo más importante para llevar a cabo estos cambios en el país era crear costumbre: "En la esfera del lenguaje la costumbre es siempre anterior á la ley, el uso precede á la regla, y las modificaciones, en vez de decretarse reflexivamente por los doctos en un momento dado, se van introduciendo lentamente por la masa común de los que hablan el idioma (y especialmente por el pueblo) de una manera espontanea. Sólo cuando la costumbre da carta de naturaleza á la reforma, es cuando se le consigna los cánones del lenguaje y adquiere fuerza de ley para lo sucesivo" (Lá Época, núm. 13441, 23 de enero de 1890: 2). 
él mismo como definitivo ${ }^{26}$, es presentado de manera sistemática a partir de diez reglas que enumeramos a continuación: 1) el sonido je se escribirá siempre $\operatorname{con} j ; 2$ ) el sonido $z e$ se representará siempre con $z$, y la $c$ tendrá en todos los casos el mismo sonido que en casa;3) el signo $r$ se empleará solo para la ere (suave) y la erre (fuerte) se escribirá siempre $r r$; 4) el sonido vocal $i$ se escribirá siempre con $i$ latina; la articulación ye, con $y$ griega; 5) toda letra que no se pronuncie en ciertos casos, se omitirá en la escritura (ej. trasposizion oscura); 6) descartar la $x$ y reemplazarla por $c s$ o $s$, según los casos; 7) se escribirá con $b$ la labial suave, suprimiéndose del alfabeto el signo $v ; 8)$ desterrar la $h$ por ser una consonante muda siempre; en las voces en que va seguida de $u e$, en las que la $u$ se articula, esta llevará diéresis; 9) las consonantes $c h, l l$ y $r r$, que se escriben actualmente con dos signos, se refundirán en uno solo para ofrecer a la vista la menor novedad posible, y 10) desterrar todas las letras mayúsculas, usando en su lugar minúsculas de un número mayor y solo después de punto final. Su aplicación da como resultado un alfabeto compuesto por 25 signos en minúsculas ( $a, b, c, c h$, $d, e, f, g, i, j, l, l l, m, n, \tilde{\mathrm{n}}, o, p, r, r r, s, t, u, y, \mathrm{ü}, z)$, un sistema casi idéntico al que unos años más tarde presenta también Jimeno Agius, si no llega a ser por la preferencia de este nuevo por la conservación de la grafía $q$ en lugar de $c$ y la ausencia en el alfabeto del signo ü (Revista contemporánea, Tomo LXXXI, vol. VI, 30 de marzo de 1891: 582-596) ${ }^{27}$.

Aunque Contreras (1994: 21-26) ha dado buena muestra de los cambios de alfabeto propuestos por los reformistas chilenos posteriores a Bello, no queremos dejar pasar la ocasión para reseñar la de aquellos más importantes

26 A este respecto, Escriche y Mieg afirma lo siguiente: "En manera alguna pretendo dar mi proyecto como un tipo acabado al que hayan de someterse los partidarios de la reforma; es sólo un proyecto más que someto al examen y á la crítica de las personas competentes en la materia, á fin de que, con el concurso de todas, lleguemos á poseer un plan modelo que sirva de norma á la campaña reformista" (Revista contemporánea, Tomo LXXV, vol. VI, 30 de septiembre de 1889: 561-580).

27 Años más tarde, propone también su propia reforma Juan Bosch Cusí en un artículo dividido en tres partes con el título "Reforma de la ortografía castellana" (El eco de la montaña, núm. 282, 28 de noviembre de 1897: 4; núm. 283, 5 de diciembre de 1897: 2; núm. 284, 12 de diciembre de 1897: 1-2). Las dos últimas entregas se destinan a la reforma del acento, mientras que la primera está centrada en el alfabeto, cuya propuesta de reforma se realiza a partir de los siguientes aspectos: a) supresión de la $h$; b) eliminación de la $v$, quedando la $b$ para sustituirla; c) supresión de la $k$ y de $q$, "dejando la $z$ (que llamaríamos ce) para el sonido linguodental, y la $c$ (con el nombre de que) para las articulaciones guturales"; d) uso de $g$ (gue) para el sonido gutural suave, y de $j$ (je) para el fuerte; e) empleo de $y$ solo en concepto de consonantes y de $i$ en todos los demás casos; f) uso de $r r$ para el sonido fuerte y de $r$ para el suave; g) supresión de $x ; \mathrm{h}$ ) abolición de la articulación inversa en $t, p, g$, sustituyéndolas por $d, b$, y $c$, respectivamente e i) no conversión de $n$ en $m$, ni tan siquiera detrás de $b$ o $p$. 
en este nuevo grupo de neógrafos de finales de siglo. En primer lugar, destacamos la figura de Lenz (1914: 26), cuya propuesta "no se trata absolutamente de reformas nuevas, sino solo de conservar la ortografía acostumbrada de Chile", que carecía a finales de siglo del seguimiento pretendido. En una línea similar, Carlos Cabezón propone un sistema de alfabeto que consta de 25 signos, en el que, al igual que Jimeno Agius, opta por la $q$ en lugar de $c$ e incluye como novedad la permanencia de $x$ en el sistema: $a, b, c h, d, e, f, g, i, j, l, l l, m, n, \tilde{\mathrm{n}}, o, p, q, r, r r, s, t, u, x, y, z .^{28}$ A pesar de que su sistema solo se aleja del de García del Río y Bello en la desaparición de $v$, la prensa chilena acusa a Carlos Cabezón de enseñar en la Escuela Naval la ortografía caprichosa del español Jimeno Agius ( $c f$. La Unión, 20 de marzo de 1892: 2), de la cual también se diferenciaba al menos en un aspecto: la presencia de $x$. Se otorga de este modo una marcada influencia del autor español en el chileno, que ha traspasado erróneamente a los estudios de historiografía lingüística, donde también, por ejemplo, Contreras (1994: 66) interpreta que el apoyo de Cabezón y Newman a la publicación de la obra de Jimeno Agius significaba un cambio en sus preferencias por la ortografía fonética propuesta por este autor. En realidad, no existe ninguna colonialización ideológica -ni en este, ni en el resto de casos de españoles cuyas obras fueron publicadas en Chile- sino simplemente una instrumentalización de sus obras e ideas, puestas al servicio de la causa que se defiende y que sirven para fortalecer la base ideológica contemporánea de la reforma en un país que en estos años adolece de textos de envergadura sobre la materia. Conviene tener en cuenta, a este respecto, que, si bien en el caso de Carlos Cabezón, estamos ante alguien con un criterio propio sobre la reforma, conocedor además de los movimientos de reforma internacionales - como demuestra en sus Notas sobre la reforma ortográfica (cf. Carlos Cabezón 1892)-, la figura de Carlos Newman entronca más bien con la de un apasionado de la cultura que, entusiasmado por los asuntos lingüísticos, destina gran parte de su fortuna a propagar la causa de la reforma ortográfica, con cuyos principios se aviene ${ }^{29}$.

28 En este punto, su postura difiere de la de Bello, que en su alfabeto de 26 letras mantiene la oposición entre $b$ y $v$, y también de la de su maestro Eduardo de la Barra (1897a: 21), que además de esa misma característica, también apuesta por mantener $k$ en el sistema en lugar de $q$.

29 Quizás esto también explique la ausencia de sus nombres en el listado de miembros chilenos en estas sociedades internacionales de reforma, como ya se ha visto previamente en el caso de Dhi Fonètik Tîtcer'z Asóciécon. 
A pesar de que todos estos reformistas suelen defender los múltiples beneficios de sus propuestas (ayuda para la lectura y escritura, menor tiempo para la escritura, ahorro en costes de imprenta...), no parece que todos estos argumentos pudieran ser esgrimidos por alguien como Fernando Araujo (1894) $)^{30}$ en su propuesta de modelo, en la que, al margen de otras particularidades, se da entrada a un conjunto de nuevos signos simples para eliminar los dígrafos $c h, l l$ y $r r$, cuya instauración era dificultosa, no solo en la escritura manuscrita, sino, fundamentalmente, en la impresa, dada la complejidad que para los editores suponía el abandono de los viejos tipos y la compra de otros nuevos para las labores de edición e impresión. Su modelo de reforma, más concretamente, consiste en un alfabeto formado por las siguientes 24 letras: $a, b, z, \tau, d, e, f, g, i, j, k, l, t, m, n, \tilde{\mathrm{n}}, o, p, q, r$, $r, s, t, u, y$.

\subsection{PLAN DE REFORMA ORTOGRÁFICA}

Teniendo en cuenta el fracaso de otras propuestas del pasado, los neógrafos centran, en general, su interés en encontrar un plan detallado que sirva para implantación de la reforma en la sociedad. En esta línea, algunos autores son conscientes del rechazo que supondría una propuesta de reforma total y brusca de la ortografía, así que se muestran partidarios de una transición gradual del sistema actual al nuevo sistema fonético de ortografía, como una manera que facilite la consecución de adeptos. Esta es la línea defendida por Escriche y Mieg, que sostiene lo siguiente: "si presento un plan de reforma perfectamente gradual, hasta llegar paulatinamente y sin violencia alguna al sistema completo que he desarrollado [...], será mucho más fácil encontrar quienes se comprometan á ser sus apóstoles" (Revista contemporánea, Tomo LXXXVI, vol. II, 30 de octubre de 1889: 183). En este sentido, propone un plan basado en tres periodos: un primer periodo en el que se incluyan innovaciones menores, que desfiguren muy poco el aspecto de la escritura (cambio de ex por es, trans por tras, pérdida del acento en $a$, o, etc.); un segundo periodo con variaciones "un poco extrañas, no muy chocantes"

30 A diferencia del resto de neógrafos españoles, Araujo publica parte de sus escritos fuera de España en relación con el movimiento de reforma francés, aunque también se ocupa de la reforma española en su obra de referencia, Estudios de fonétika kastellana, un trabajo confeccionado a petición de los neógrafos chilenos cuyo origen está en una serie de artículos que, bajo el nombre de "Recherches sur la phonétique espagnole", había salido a la luz primeramente en la revista alemana Phonetische Studien y que -como indica (Muñiz Cachón 2009: 495)- es "el punto de partida de la descripción fonética del castellano y la primera obra en nuestra lengua que aborda la Fonética como disciplina independiente". 
(entre las que señala la rectificación en el uso de $i$ e $y$, la sustitución de $x$ por $c s$, etc.), y un tercer periodo con "las innovaciones de más bulto, más repulsivas" (entre las que incluye el abandono de la $h$ y la $v$, la adopción de nuevos signos, etc.).

Puesto que las esperanzas de que exista una cooperación temprana por parte de la Academia son nulas, los neógrafos ponen sus ojos en la prensa para iniciar el proyecto de reforma. A juicio de Escriche y Mieg, "no es dudosa la elección, y desde luego salta á la vista que el más eficaz, el primero á que debemos volver los ojos es la prensa" (Revista contemporánea, Tomo LXXXVI, vol. IV, 30 de noviembre de 1889: 419). De este modo, los neógrafos intentan ocupar las páginas de los periódicos para hacer valer sus propuestas y difundirlas en la sociedad, si bien hay un objetivo más ambicioso detrás de este: convertir los periódicos en baluartes de su causa, intentando que estos adopten las simplificaciones ortográficas en sus ediciones o, al menos, autoricen la publicación de sus artículos escritos con la ortografía reformada. Un logro de difícil consecución, pues no parecía haber problemas en que los periódicos pusieran a disposición de los neógrafos sus páginas para la exposición de sus ideas, pero cosa distinta era el uso de una ortografía no oficial en sus páginas que, aparte de dificultar la labor de sus editores, podía hacer peligrar la fidelidad de sus lectores o perjudicar los intereses comerciales del periódico. Esta es la razón por la cual Jimeno Agius ve poco viable que algún periódico de gran circulación adopte la reforma para su escritura (Revista contemporánea, Tomo LXXXI, vol. V, 15 de marzo de 1891: 481) y, de hecho, en el ámbito español, son pocos los autores que consiguen publicar sus textos en ortografía reformada. Destaca, entre ellos, Onofre Antonio de Naverán, un maestro de la escuela de Guernica que, partidario de esta corriente radical de la fonografía, aboga por una transformación inmediata y total de la escritura que ejecuta en sus propias publicaciones, con una grafía reformada que sirve de ejemplo de propaganda:

En tanto llege ese día, trabajaremos, sobre todo kon el ejemplo, ke, komo azertadamente dize Mr. Bréal, es el mejor medio de propagación y enseñanza; rrazon que me á movido a eskribir, según lo é eho en otros kasos análogos, estas kuartillas, no kon la ortografía oficial ó akadémika, sino fonográfikamente, no sea ke de mí se diga ke bendo konsejos i no los tengo para mí (La Escuela Moderna, mayo de 1892: 337) ${ }^{31}$.

31 Como venía siendo habitual en la época, el texto adopta forma de folleto y sale publicado al año siguiente en Guernica (Naverán 1893), tal y como se anuncia en la prensa, que lo acoge con buena crítica (El Día, núm. 4827, 29 de septiembre de 1893: 4). 
Otra figura destacable en este sentido es Jimeno Agius, en quien se observa una evolución desde una posición inicial conservadora a otra más radical. Aunque desde sus primeros textos manifiesta la importancia de poner en práctica la ortografía reformada ( $c f$. Revista contemporánea, Tomo LXXXI, vol. V, 15 de marzo de 1891: 481-482), lo cierto es que no la lleva a cabo en sus escritos hasta la publicación de sus "Naderías" (Revista contemporánea, Tomo CIII, vol. IV, 30 de agosto de 1896: 364-379; Tomo CIII, vol. V, 15 de septiembre de 1896: 523-542; Tomo CIII, vol. VI, 30 de septiembre de 1896: 653-660; Tomo CIV, vol. I, 15 de octubre de 1896: 38-48; Tomo CIV, vol. II, 30 de octubre de 1896: 195-203; Tomo CIV, vol. III, 15 de noviembre de 1896: 297-304; Tomo CIV, vol. IV, 30 de noviembre de 1896: 425-435), un conjunto de artículos que justo al año siguiente ve la luz en forma de folleto bajo el título de Naderías. Qoleqzión de artíqulos sobre asuntos gramatiqales ( $c f$. Jimeno Agius, 1897) y en el que este autor cambia también la grafía de su apellido a Ajius (Jimeno Agius 1897).

En el ámbito chileno, tampoco los periódicos son muy proactivos con los ideales reformistas, pero, en este caso, la actitud de sus neógrafos es en general más radical y combativa que la de los españoles, haciendo uso práctico de las reformas en sus publicaciones sobre ortografía y también en otras tantas obras de diversa temática, como puede comprobarse en el listado de libros, folletos y artículos que se incluyen en Cabezón (1897: 13-16) o, más recientemente, en Glickman (1984) ${ }^{32}$. En su contra, la recién fundada Academia Chilena de la Lengua y el propio Consejo de Instrucción Pública, que no ven con buenos ojos la presencia de los distintos sistemas de escritura que se producen en el país y que dificultan el proceso de enseñanza de la lengua en la escuela ${ }^{33}$.

32 El caso de Echeverría y Reyes (1895: 5) es excepcional en estos años en Chile. A pesar de mostrarse partidario del fonetismo, aboga por una reforma pausada: "como el uso de la jente ilustrada no ha admitido aun todas estas teorías, por ahora nos limitamos a insinuar las reformas que, con el tiempo, será preciso aceptar en nuestra escritura", Junto a él, destaca también E. de la Barra, un autor cuya formación y proceso de ideologización provienen de una época anterior y que -como explicita Martínez Alcalde (2012: 113-115) - acude a la historia de la ortografía para legitimar su propia propuesta, basada en este caso en un plan de reforma gradual, mediante la introducción escalonada de cambios en la escritura ( $c f$. E. de la Barra, 1897b: 61-64).

33 Los problemas con el uso de distintos sistemas ortográficos no eran nuevos ni habían surgido con el movimiento neógrafo, sino que ya venían de antes. En la prensa española ya se había caricaturizado, de hecho, la situación chilena con la siguiente noticia, aparecida en La Época (núm. 13336, 7 de octubre de 1889: 3): "Tiene gracia el siguiente apuro en que el Gobierno chileno acaba de colocar á los habitantes de aquel país, según vemos en Las Novedades de Nueva York. El Ministro de Hacienda ha prohibido el uso de la ortografía de 
En líneas generales, los neógrafos chilenos consideran necesario el abandono inmediato de las imposiciones académicas y la instauración de lo que ellos denominan una ortografía 'rrazional' que tenga como base el fonetismo y en la que cada letra represente un solo sonido de la lengua. Frente a las propuestas anteriores de autores como Bello y Sarmiento, estos neógrafos no buscan en su propuesta de cambio un impacto en la alfabetización y el desarrollo de la nación chilena, sino una reivindicación de lo que ellos consideran un derecho individual:

Pregúntanse muchos qon qé faqultad i derecho un indibiduo puede permitirse esqribir de un modo distinto a la mayoría, i atropellar las reglas de la gramátiqa i el uso. Sólo el poner en duda el derecho qe qada qual tiene de ablar i esqribir como le plazqa o qomo lo qrea mas razional i menos trabajoso, está probando qe los qe tal obserbazion azen son prodijios de un atabismo inteleqtual (Cabezón, 1892: 54).

\section{CIERRE}

Tras los intensos debates ortográficos vividos en España y Chile a mediados del XIX, el final de este siglo se caracteriza por lo que hemos denominado el resurgimiento de la neografía, una nueva ola de reformistas que afrontan sus reivindicaciones de cambios ortográficos del español en el marco de los distintos movimientos internacionales a favor del fonetismo, cuya creciente

la Academia Española en las oficinas de su dependencia, ordenando la ortografía de Andrés Bello. Y á renglón seguido de esta orden han dictado otra el Consejo de Instrucción Pública y el Ministro del Interior, disponiendo el uso de la ortografía española. Desde ahora tienen casi todos los chilenos que volver á la escuela, porque en las dependencias de hacienda han de ir con arreglo á las prescripciones de Bello, y no olvidar tampoco la ortografía de la Academia por si les ocurre algo en Gobernación ó en Fomento".

Esta anarquía ortográfica llega hasta las primeras décadas del XX, como puede inferirse a partir de la siguiente advertencia por parte del Consejo de Instrucción Pública para que no se tenga en cuenta la ortografía: "Del marco general de inestabilidad política en Chile y del caos en materia de norma ortográfica que precedieron a esta decisión es una muestra la directiva del Consejo de Instrucción Pública del 6 de noviembre de 1911, en la que se advertía a las comisiones examinadoras de castellano "que no deben exigir a los examinados un sistema ortográfico determinado, y que, a este efecto, deben únicamente atender a la ortografía adoptada por el establecimiento particular a que pertenecen los alumnos", o bien "a la que cada uno de los examinandos privados declare seguir"' (extraído de Martínez Alcalde 2010: 78-79). 
repercusión y difusión a través de la prensa fortalecen su ideología a favor de la reforma. No estamos ante un grupo cohesionado del que estos autores forman parte de manera consciente, más allá de sus anhelos por la defensa de una misma causa y el intercambio de publicaciones que sirve de impulso y apoyo a sus ideas; sus discursos carecen de originalidad y con frecuencia abordan el asunto sin novedades, al margen de esa petición constante entre los españoles para que se imiten los modelos de asociacionismo internacional, una quimera tan inalcanzable como, a la postre, resulta el resto de objetivos propuestos: ni la Real Academia Española ni la Academia Chilena de la Lengua se adhieren al movimiento de reforma; los neógrafos tampoco son capaces de abanderar un proyecto común que permita la creación de una sociedad en el ámbito hispánico que sirva de defensa de sus ideas, así como de gancho para la connivencia de un importante medio como la prensa, que podría haber ejercido un papel fundamental en la puesta en marcha de los cambios propuestos. La existencia de diferentes modelos de reforma entre estos intelectuales no ayuda a la ejecución de los cambios ortográficos, pero, ciertamente, ningún periódico de la época (salvo los que sirven de órgano de algunas de las sociedades internacionales de reforma) está dispuesto a sacrificar sus intereses comerciales para la defensa de esta causa, de ahí que, por lo general, la prensa no permita la reproducción de sus ediciones en 'ortografía razional' o reformada, más allá de las pinceladas de algunos de los artículos de estos neógrafos, que aparece en sus páginas como mera anécdota costumbrista. Esto no es obstáculo alguno para que consideremos la prensa escrita de la época como la principal arma de difusión de la que se valen estos neógrafos. Un medio, sin embargo, ineficaz para que las propuestas de cambio alcancen repercusión alguna en el sistema educativo, de manera particular, pero tampoco en otros ámbitos de las sociedades española y chilena, donde las acciones de estos reformistas quedan reducidas casi exclusivamente a un conjunto de artículos, obras propias y traducciones por parte de un grupo de intelectuales que, en un ejercicio público de libertad de escritura y opinión, muestran su disconformidad con las imposiciones gubernamentales y las doctrinas académicas imperantes, vertiendo acaso una necesaria dosis de caos dentro de un sistema perfectamente regulado por la docta institución, pero insuficiente para dar un giro a su autoridad reguladora en la codificación lingüística del español. 


\section{REFERENCIAS BIBLIOGRÁFICAS}

Araujo, Fernando. 1894. Estudios de fonétika kastetana. Santiago de Chile.

BARRA, EduARdo De LA. 1897a. Ortografía fonética. Santiago de Chile: Establecimiento Poligráfico Roma.

1897b. La reforma ortográfica. Su historia i su alcance. Santiago de Chile: Imprenta i encuadernación Barcelona.

CABezón, CARLos. 1892. Notas sobre la reforma ortográfiqa. Santiago de Chile: Imprenta Barzelona.

1896. Neógrafos kontemporáneos. Tentatiba bibliográfika. Santiago de Chile: Imprenta Zerbántes.

1897. La ortografia rrazional. Quillota.

Cáceres, Valentina y Darío Rojas. 2019. Rodolfo Lenz y la reforma ortográfica chilena: ciencia, tradición y política del lenguaje. Boletín de Filología 54(1): 65-93.

Contreras, Lidia. 1993. Historia de las ideas ortográficas en Chile. Santiago: Centro de Investigaciones Diego Barros Arana. 1994. Ortografia y grafemática. Madrid: Visor.

EcheVerría y Reyes, Anibal. 1895. Prontuario de la ortografía castellana usada con particularidad en Chile. Santiago de Chile: Imprenta de "La Gaceta".

EsCriche y Mieg, TomÁs. 1889. Reforma de la ortografía castellana. Tipografía de Manuel Ginés Hernández: Madrid. Bilbao.

1890. Reforma de la ortografía castellana. $2^{\text {a }}$ edición. Tipografía C. Lucena y Cía.:

Esteve Serrano, Abraham. 1982. Estudios de teoría ortográfica del español. Murcia: Universidad de Murcia.

Firmin Didot, Ambroise. 1867. Observations sur l'orthographe ou ortographie française. Paris: Typographie de Ambroise Firmin Didot.

Galazzi, EnRica. 2000. L'Association Phonétique Internationales. En S. Auroux (ed.). Historie des idées linguistiques, Tome 3, pp. 499-516. Sprimont: Mardaga.

GaviÑo Rodríguez, Victoriano. 2020a. Ideologías lingüísticas en la prensa española del siglo XIX: neógrafos frente a academicistas por la ortografía del español. En Borja Alonso Pascua, Francisco Escudero Paniagua, Carlos Villanueva García, Carmen Quijada Van den Berghe y José J. Gómez Asencio (eds.). Lazos entre lingüística e ideología desde un enfoque historiográfico (ss. XVI-XX), pp. 85-104. Salamanca: Ediciones Universidad de Salamanca.

2020b. Epígonos del reformismo ortográfico en España tras la oficialización de la doctrina académica (1844-1868). RLA. Revista de Lingüística Teórica y Aplicada 58 (1): 135-158.

GLICKMAN, ROBERTO JAY. 1984. Los que se atrevieron a ser diferentes: notas sobre la ortografía rrazional en Chile a fines del siglo XIX y principios del siglo XX. En Actas del VII Congreso de la Asociación de Lingüistica y filología de América latina (ALFAL). Homenaje a Pedro Henríquez Ureña, Tomo I, pp. 419-435. Santo Domingo: Editorial Universidad Nacional Pedro Henríquez Ureña.

Gómez de Salazar, Condomines y Bosch. 1872. La neografia. Polémica sobre reformas ortográficas entre los señores Gómez de Salazar, Condomines y Bosch. Palma: Imprenta de Pedro José Gelabert.

Havet, Louis. 1890. La simplification de l'orthographe. Paris: Librairie Hachette et Cie. 1892a. Reforma de la ortografia castellana. Valparaíso: Imprenta de la Patria. 
Jimeno Agius, José. 1892b. Reforma de la ortografía castellana. Segunda edición. París: Franzisqo Enrríqez.

1897. Naderías. Qoleqzión de artíqulos sobre asuntos gramatiqales. Madrid: Imprenta de los Hijos de M. G. Hernández.

Lenz, Rodolfo. 1914. De la Ortografía castellana. Segunda edición. Valparaíso: Franzisko Enrríkez.

LitTré, Émile. 1873-1874. Dictionnaire de la langue française. 4 volumes. Paris: Librairie Hachette et $C$. ie

MacMahon, Michael K. C. 1986. The International Phonetic Association: The first 100 years. Journal of the International Phonetic Association 16: 30-38.

Martínez AlCalde, María José. 2010. La fijación ortográfica del español: norma y argumento historiográfico. Bern: Peter Lang.

2012. Ortografía. En Alfonso Zamorano Aguilar (coord. y ed.). Reflexión lingüistica y lengua en la España del siglo XIX: marcos, panorama y nuevas aportaciones, pp. 95115. München: Lincom.

MartíneZ de Sousa, José. 1991. Reforma de la ortografía española. Madrid: Visor Libros.

MuÑIz CACHÓN, CARMEN. 2009. Fernando de Araujo en los orígenes de la fonética hispánica. En José María García Martín (dir.) y Victoriano Gaviño Rodríguez (ed.). Las ideas y realidades lingüísticas en los siglos XVIII y XIX, pp. 483-497. Cádiz: Servicio de Publicaciones de la Universidad de Cádiz.

Naverán, OnOfRe ANTONio De. 1893. El fonetismo i la pedagojía. Gernika i Luno: Imprenta de Antonio Egurola.

Puche Lorenzo, Miguel Ángel. 2019. El DRAE (1817-1852) a través de la prensa española. En Dolores Azorín, Gloria Clavería y Enrique Jiménez Ríos (eds.). ELUA: El diccionario de la Academia y su tiempo: lexicografia, lengua y sociedad en la primera mitad del siglo XIX, Anexo V: 65-88.

Villalaín Benito, José Luis. 1997. Manuales escolares en España. Tomo I. Legislación (1812-1939). Madrid: UNED.

Villarroel, Natalia. 2019a. Los neógrafos chilenos y la ortografía rrazional: un proyecto lingüístico anarquista, CUHSO 29(2): 125-153.

2019b. La práctica ortográfica del movimiento neógrafo chileno como acto glotopolítico. Logos: Revista de Lingüística, Filosofia y Literatura 29(2): 348-363. 